\title{
Breeding Particle Swarm Optimization for Railways Rolling Stock Preventive Maintenance Scheduling
}

\author{
Tarek Aboueldah', Hanan Farag² \\ ${ }^{1}$ Research and Development: Ministry of Transport, Cairo, Egypt \\ ${ }^{2}$ Faculty of Graduate Studies for statistical Research, Department: Management \& Operations Research, Cairo University, \\ Cairo, Egypt \\ Email: heshoaboda@yahoo.com,hhhfarag@yahoo.com
}

How to cite this paper: Aboueldah, T. and Farag, H. (2021) Breeding Particle Swarm Optimization for Railways Rolling Stock Preventive Maintenance Scheduling. American Journal of Operations Research, 11, 242-251. https://doi.org/10.4236/ajor.2021.115015

Received: August 2, 2021

Accepted: September 7, 2021

Published: September 10, 2021

Copyright ( 2021 by author(s) and Scientific Research Publishing Inc. This work is licensed under the Creative Commons Attribution International License (CC BY 4.0).

http://creativecommons.org/licenses/by/4.0/

\begin{abstract}
The goal of railway rolling stock maintenance and replacement approaches is to reduce overall cost while increasing reliability which is multi objective optimization problem and a proper predictive maintenance scheduling table should be adequately designed. We propose Breeding Particle Swarm Optimization (BPSO) model based on the concepts of Breeding Swarm and Genetic Algorithm (GA) operators to design this table. The practical experiment shows that our model reduces cost while increasing reliability compared to other models previously utilized.
\end{abstract}

\section{Keywords}

Railways Rolling Stock, Predictive Maintenance Scheduling Table, Multi Objective Optimization Problem, Breeding Particle Swarm Optimization

\section{Introduction}

Railway rolling stock preventive maintenance is usually carried out at predetermined regular time/mileage intervals based on the knowledge and experience of train operating companies, rolling stock owners, original equipment manufacturers [1]. As a result, a significant portion of railway maintenance resources (e.g. budget, time, manpower) are wasted due to insufficiency or inefficiency of proper timing of preventive maintenance and replacement [2]. Thus, many predictive maintenance scheduling tables to reduce overall costs whilst keeping highest possible reliabilities have been introduced, for example, a predictive maintenance system to railways turnouts (switches) by integrating two common types of main- 
tenance techniques, reliability centered maintenance and remote condition monitoring [3]. A multi-objective model to optimize the inspection and maintenance procedures with respect to both economic and safety objectives during railway track inspection have been proposed [4]. Railways rolling stocks have been proven to be repairable systems represented by non homogeneous data [5] where Rate of Occurrence of Failures (ROCOF) has a trend and can be predicted by Power Law Non Homogeneous Poisson Process (NHPP) [6]. Previous studies have used Power law NHPP to predict (ROCOF) in railways, for example Bayesian Neural Network (BNN) has been used for predicting failures in underground trains [7] and predicting the stochastic degradation process of metro rails to design maintenance activities scheduling [8]. Reliability-based techniques were used to develop a predictive model for failure rate probability of point-and-point machines in railway signalling subsystems [9]. The prediction model of expected number of rail defects using failure parameters estimation was introduced [10] and the newcast model is used to predict the conditions of switches and crossings in Swedish railways [11]. Based on available failures and maintenance records for 5M25 motor coach of Metrorail fleet at the salt River Depot in Cape town, South Africa [6] [7] a predictive maintenance scheduling table for railways rolling stock based on reliability and cost was introduced [12]. In Section 2 the mathematical model of the multi objective optimization problem representing the predictive maintenance scheduling table is reviewed and in Section 3 we present our proposed Breeding Particle Swarm Optimization (BPSO) based on introducing Genetic Algorithm (GA) operators and swarm division into breeding portion and discarded portion. In Section 4, based on the available data [5] [6] [12], we will compare the output cost and reliability of our proposed predictive maintenance scheduling table with those obtained in [12].

\section{Mathematical Model}

The objective of the predictive maintenance scheduling table in railways rolling stocks is to find the optimum solution that minimize the maintenance cost and maximize the system reliability [13]. To achieve it, a multi objective mathematical model is formulated with the following parameters.

$N$ : Number of components,

J: Number of periods,

T: planning horizon length,

$\gamma_{i}$ : Failure function parameter of component $i$,

$\delta_{i}$ : Improving/degradation parameter of component $i$,

$\alpha_{i}$ : Age reduction factor of preventive maintenance of component $i$,

$\alpha_{i}=0$ if replacement, 1 if no changes, $0<\alpha_{i}<1$ if maintenance,

$E_{i, j}$ : Expected number of failures of component $i$ in the period $j$,

$F_{i}$ : Failure cost of component $i$,

$M_{i}$ : Preventive maintenance cost of component $i$,

$R_{i}$ : Replacement cost of component $i$, 
$Z$ : Opportunity cost of downtime of the overall system,

$R R$ : Required reliability of the overall system,

The decision variables are as follows,

$X_{i, j}$ : Effective age of component $i$ at the start of period $j$,

$X_{i, j}^{+}$: Effective age of component $i$ at the end of period $j$,

$m_{i, j}$ : Equals one if component $i$ at period $j$ is maintained and zero otherwise,

$r_{i, j}$ : Equals one if component $i$ at period $j$ is replaced and zero otherwise.

$$
\begin{gathered}
X_{i, j}^{+}=X_{i, j}+T / J, i=1,2, \cdots, N ; j=1,2, \cdots, J \\
X_{i, j+1}=\alpha_{i} \times X_{i, j}^{+}
\end{gathered}
$$

These two equations indicate that the effective age $X_{i, j+1}$ will be zero if component $i$ is replaced, the same as the effective age $X_{i, j}^{+}$if nothing occurred and equals $X_{i, j}^{+}$reduced by $\alpha_{i}$ if maintenance occurred.

Assuming that the components failure corresponds to a power law Non Homogeneous Poisson Process (NHPP) where the Rate of Occurrence of Failures (ROCOF) is not a function of time, so the expected number of failures of component $i$ at period $j$ can be written as follows

$$
E_{i, j}=\gamma_{i} \times\left[\left(X_{i, j}^{+}\right)^{\delta_{i}}-\left(X_{i, j}\right)^{\delta_{i}}\right]
$$

The failure cost $F_{i, j}$ of component $i$ at period $j$ is

$$
F_{i, j}=F_{i} \times E_{i, j}
$$

The maintenance cost $M_{i, j}$ and replacement cost $R_{i, j}$ of component $i$ at period $j$ are

$$
\begin{gathered}
M_{i, j}=M_{i} \times m_{i, j} \\
R_{i, j}=R_{i} \times r_{i, j}
\end{gathered}
$$

The overall cost over the whole planning horizon is as follows:

$$
\text { Cost }=\sum_{i=1}^{N} \sum_{j=1}^{J}\left(F_{i, j}+M_{i, j}+R_{i, j}\right)+\sum_{j=1}^{J} Z
$$

As the railways rolling stocks components are linked in series which mean that a failure in any components leads to the overall system failure [7] [12], so the reliability of component $i$ at the start of period $j$ is defined as

$$
R R_{i, j}=\mathrm{e}^{-E_{i, j}}=\mathrm{e}^{-\left(\gamma_{i} \times\left[\left(X_{i, j}^{+}\right)^{\delta_{i}}-\left(X_{i, j}\right)^{\delta_{i}}\right]\right)}
$$

The system reliability at the end of the period $j$ is

$$
R R_{j}=\prod_{i=1}^{N} R R_{i j}
$$

The overall reliability over the whole planning horizon is as follows:

$$
R R=\prod_{j=1}^{J} R R_{j}
$$

Thus, the required predictive maintenance scheduling table, is a multi objective optimization problem to maximize reliability and minimize cost subject to the following constraints. 


$$
\begin{gathered}
\forall i=1,2, \cdots, N \text { and } \forall j=1,2, \cdots, J \\
X_{i, j}, X_{i, j}^{+} \geq 0, m_{i, j}+r_{i, j}=0 \text { or } 1 \\
X_{i, j}=\left(1-m_{i, j-1}\right) *\left(1-r_{i, j-1}\right) X_{i, j-1}^{+}+m_{i, j-1} * \alpha_{i} * X_{i, j-1}^{+}
\end{gathered}
$$

The fitness function could be written based on weighted summation method [14] as follows.

$$
\text { fitness }=w_{1} * \frac{\text { Cost }}{\text { Cost }_{\max }}-w_{2} * \frac{R R}{R R_{\max }}
$$

where $w_{1}, w_{2}$ are arbitrary selected determination factors subject to $w_{1}+w_{2}=1$. Alternatively, the fitness function can be written based on the difference between the reliability $R R$ and the required reliability $R R_{\text {req }}[14]$ as follows.

$$
\text { fitness }=\frac{\text { Cost }}{\text { Cost }_{\max }}+\left|R R_{\text {req }}-R R\right|
$$

\section{Breeding Particle Swarm Optimization (BPSO)}

Stochastic search algorithms such as Simulated Annealing (SA) and Genetics Algorithm (GA) include premature convergence due to the quick losing of diversity. The concept of PSO is based on finding the global best particle as the optimal particle and all the other particles learn from it can bring in keeping the diversity [15]. However in multi objective optimization problem where the problems are complex with many local optima and the local optimums are near to the global optimum, thus the PSO can easily trapped in local optima [16]. In order to promote the search diversity in the PSO to ensure global search (exploration) while maintaining the local search (exploitation), we propose Breeding Particle Swarm Optimization (BPSO) by adding GA operators to PSO as follows:

According to the traditional PSO concept [17], each particle $P_{l}$ in the swarm of size $L$ represents a solution of the multi objective optimization problem where $l=1,2, \cdots, L$ and the swarm moves from one generation $g$ to another where $g=1,2, \cdots, G$.

At any new generation $g$ particles' new fitness function $F\left(P_{l}^{\text {new }}\right)$ for all particles are evaluated, the particle best fitness function $F\left(P_{\text {lbest }}\right)$ and the global best fitness function $F\left(P_{\text {best }}\right)$ are adjusted according to:

$$
F\left(P_{l}^{\text {new }}\right)= \begin{cases}F\left(P_{\text {lbest }}\right) & F\left(P_{\text {lbest }}\right) \geq F\left(P_{l}^{\text {new }}\right) \\ F\left(P_{\text {best }}\right) & F\left(P_{\text {best }}\right) \geq F\left(P_{l}^{\text {new }}\right)\end{cases}
$$

where $F\left(P_{\text {best }}\right)=\min \left(F\left(P_{\text {lbest }}\right)\right), \quad \forall l=1,2, \cdots, L$.

The BPSO is designed as follows:

The swarm will be divided into two portions, the first is the discarded portion $(L * \Psi)$ containing the worst particles fitness function where $\Psi$ is the arbitrary selected breeding ratio between zero and one and the other is the breeding portion which is the remaining $(L *(1-\Psi))$ particles [18].

Select randomly two particles from the breeding portion as old parent parti- 
cles $\left(P_{l 1}^{\text {old }}, P_{l 2}^{\text {old }}\right)$ where, $l_{1}, l_{2}=1,2, \cdots, L *(1-\Psi), \quad L_{1} \neq L_{2}$.

To increase the diversity in the search space while keeping the reinforcement searching direction [19] one of the parent particles will be subjected to GA inversion operator while the other to GA swap operator yielding the new modified particles $\left(P_{l 1}^{\bmod }, P_{l 2}^{\text {mod }}\right)$.

GA swap operator selects two random chromosomes among old particle $P_{l}^{\text {old }}$ chromosomes and changes their location to get new modified particle $P_{l}^{\text {mod }}$.

GA inversion operator selects two chromosomes randomly among old particle $P_{l}^{\text {old }}$ chromosomes and changes their location and locations between them to get new modified particle $P_{l}^{\text {mod }}$.

For example if $P_{l}^{\text {old }}$ is (2 6315748 ) and the two chromosomes 3, 7 are selected for GA swap operator, thus $P_{l}^{\text {mod }}$ will be $(26715348)$ and if they are selected for GA inversion operator $P_{l}^{\bmod }$ will be (2 6751348$)$.

These modified particles $\left(P_{l 1}^{\text {mod }}, P_{l 2}^{\text {mod }}\right)$ will replace old particles $\left(P_{j 1}^{\text {old }}, P_{j 2}^{\text {old }}\right)$ from the discarded portion where, $j_{1}, j_{2}=1,2, \cdots, N * \Psi, j_{1} \neq j_{2}$ and this step continues till replacing all discarded swarm particles.

To ensure the balancing between the global search (exploration) and the local search (exploitation) [20], the balancing ratio $\mu$ is an arbitrary selected ratio between zero and one is applied to the discarded portion to determine which modified particles $P_{i}^{\text {mod }}$ will be subjected to GA insertion operator to get new particles $P_{i}^{\text {new }}$.

Insertion operator: selects two random chromosomes and shifts the one to the position after the second one.

For example if $P_{l}^{\bmod }$ is $(26315748)$ and the two chromosomes 3, 7 are selected for GA insertion operator, thus $P_{l}^{\text {new }}$ will be (2 6157348$)$.

\section{Results and Discussion}

Predictive maintenance scheduling table for railways rolling stock will be designed to be compared with the previous one [12] designed for motor coach type 5M2A of Metrorail fleet which is a subsidiary of the Passenger Rail Service in South Africa (PRASA) at the Salt River Depot in Cape Town [5]. Failure data consisting of number of failure, time between failures, and cumulative failures for 5M2A motor coach component was obtained from the Fleet Maintenance Management System (FMMS) in the period between 2003 and 2014 and this data is listed in [5]. According to reliability trend test carried out using both Laplace and Lewis Robinson trend test [21] [22], the components reliability has a degraded trend and is represented by Power Law NHPP and the parameters are estimated using least square method and their values are shown in Table 1 [5] [6] [12].

The number of periods $J$ is 36 months, the planning horizon length $T$ is 36 and opportunity cost $Z$ is 500,000 Rands [12]. The number of generation $G$ is 500 , the number of particles $L$ is 200 as done in [12], in BPSO, the breeding ratio $\Psi$ is set to be 0.5 as done in [18], and the balancing ratio $\mu$ is selected to be 0.5 . 
Table 1. Parameters estimated values.

\begin{tabular}{cccccccc}
\hline $\mathrm{N}$ & Component Name & $\gamma_{i}$ & $\delta_{i}$ & $\alpha_{i}$ & $F_{i}$ & $M_{i}$ & $R_{i}$ \\
\hline 1 & Auxiliary Power Supply (MA/MG) & 0.00238 & 1.6210 & 0.7 & 400,720 & 20,000 & 320,000 \\
2 & Exhauster Motor & 0.00012 & 2.2129 & 0.7 & 210,720 & 65,000 & 85,000 \\
3 & Compressor Motor & 0.00263 & 1.5298 & 0.7 & 222,720 & 40,000 & 120,000 \\
4 & Traction Motor & 0.00004 & 2.5518 & 0.7 & 340,720 & 70,000 & 210,000 \\
\hline
\end{tabular}

In our experiment, MATLAB $2014 \mathrm{~b}$ is used to develop the predictive maintenance scheduling table using BPSO and it took an average of 5 minutes to solve each run. Our experiment is conducted in the two different cases similar to the cases done in [12], in Case 1 the weighted sum fitness function (equation no. 11) is used where $w_{1}$, is set to be 0.7 and $w_{2}$ is set to be 0.3 [12] while Case 2 the required reliability fitness function is used (equation no. 12) where $R R_{r e q}$ is set to be 0.5 [12]. The cost and reliability associated with the predictive maintenance scheduling table using BPSO are compared with those in [12] using (SA) and (GA) and the comparison results are shown in Table 2.

The predictive maintenance scheduling table for Case 1 and Case 2 using GA have been previously introduced in [12] and are shown in Table 3 and Table 4 respectively. The predictive maintenance scheduling table for Case 1 and Case 2 using BPSO are shown in is shown in Table 5 and Table 6 respectively where R denotes replacement operation and $\mathrm{M}$ denotes maintenance operation.

The monthly reliability associated to the predictive maintenance scheduling table using BPSO for Case 1 and Case 2 are shown in is shown in Figure 1 and Figure 2 respectively.

Referring to Table 2, for both Case 1 and Case 2, SA gives higher reliability than GA but doesn't give lower cost; the reason is that SA applies higher number of preventive maintenance and replacement activities compared to GA. As the design of predictive maintenance scheduling table is a multi objective optimization problem where the objectives are increasing the reliability and reducing the cost, our experimental result shows that both SA and GA could not properly satisfy these objectives. On the contrary, our proposed BPSO gives higher reliability than both of them and in the same time reduces the cost achieving the required objectives. Using BPSO, the number of activities is significantly reduced compared to SA leading to avoid SA drawbacks and in the same time the concept of breeding swarm increases the searching capability by discovering new directions in the search space (global search) while maintaining the reinforcement direction (local search) leading to avoid GA drawbacks.

For Case 1, Referring to Table 3 and Table 5, the predictive maintenance scheduling table for both GA and BPSO has no similar activities in any months during the whole interval (36 months), moreover, only four months are commons in activities (months no. 3, 6, 9, 33) during the whole interval. Thus, BPSO makes global search to explore new regions in the search space leading to discover better solutions than GA. 
Table 2. Comparison results.

\begin{tabular}{|c|c|c|c|c|}
\hline & \multicolumn{4}{|c|}{$\begin{array}{c}\text { Case } 1 \\
w_{1}=0.7, w_{2}=0.3\end{array}$} \\
\hline & Cost & Overall Reliability & Monthly Average Reliability & No. of Activities \\
\hline SA & $20,043,091.06$ & $51.62 \%$ & $98.18 \%$ & $R=44, M=38$ \\
\hline GA & $12,623,229.98$ & $50.3 \%$ & $98.11 \%$ & $R=35, M=2$ \\
\hline \multirow[t]{3}{*}{ BPSO } & $12,579,732.45$ & $52.03 \%$ & $98.2 \%$ & $R=38, M=1$ \\
\hline & \multicolumn{4}{|c|}{$\begin{array}{c}\text { Case } 2 \\
R R_{\text {req }}=0.5\end{array}$} \\
\hline & Cost & Overall Reliability & Monthly Average Reliability & No. of Activities \\
\hline SA & $17,787,577.04$ & $51.62 \%$ & $98.18 \%$ & $R=44, M=24$ \\
\hline GA & $12,834,562.76$ & $50.3 \%$ & $98.11 \%$ & $R=37, M=2$ \\
\hline BPSO & $12,510,299.90$ & $51.94 \%$ & $98.2 \%$ & $R=38, M=0$ \\
\hline
\end{tabular}

Table 3. Predictive maintenance scheduling table for case 1 using GA (reliability $=50.3 \%$, Cost $=12,623,229.98$ Rands).

\begin{tabular}{ccccccccccccc}
\hline Month No. & 3 & 6 & 9 & 13 & 16 & 18 & 20 & 22 & 26 & 29 & 31 & 33 \\
\hline Equipment & & & & & & & & & & & \\
\hline MA/MG & $\mathrm{R}$ & $\mathrm{R}$ & $\mathrm{R}$ & $\mathrm{R}$ & $\mathrm{R}$ & $\mathrm{R}$ & $\mathrm{M}$ & $\mathrm{R}$ & $\mathrm{R}$ & $\mathrm{R}$ & $\mathrm{M}$ & $\mathrm{R}$ \\
Exhauster Motor & $\mathrm{R}$ & $\mathrm{R}$ & $\mathrm{R}$ & $\mathrm{R}$ & - & $\mathrm{R}$ & - & $\mathrm{R}$ & $\mathrm{R}$ & - & $\mathrm{R}$ & - \\
Compressor Motor & $\mathrm{R}$ & $\mathrm{R}$ & $\mathrm{R}$ & $\mathrm{R}$ & $\mathrm{R}$ & $\mathrm{R}$ & $\mathrm{R}$ & $\mathrm{R}$ & $\mathrm{R}$ & $\mathrm{R}$ & $\mathrm{R}$ & $\mathrm{R}$ \\
Traction Motor & - & $\mathrm{R}$ & - & $\mathrm{R}$ & - & $\mathrm{R}$ & - & $\mathrm{R}$ & - & $\mathrm{R}$ & - & - \\
\hline
\end{tabular}

Table 4. Predictive maintenance scheduling table for case 2 using GA (reliability $=50.3 \%$, Cost $=12,834,562.76$ Rands).

\begin{tabular}{|c|c|c|c|c|c|c|c|c|c|c|c|}
\hline $\begin{array}{l}\text { Month No. } \\
\text { Equipment }\end{array}$ & 3 & 7 & 9 & 12 & 14 & 17 & 21 & 24 & 27 & 30 & 33 \\
\hline MA/MG & $\mathrm{R}$ & $\mathrm{R}$ & $\mathrm{R}$ & $\mathrm{R}$ & $\mathrm{R}$ & $\mathrm{R}$ & $\mathrm{R}$ & $\mathrm{R}$ & $\mathrm{R}$ & $\mathrm{R}$ & $\mathrm{R}$ \\
\hline Exhauster Motor & $\mathrm{R}$ & M & $\mathrm{R}$ & - & $\mathrm{R}$ & $\mathrm{R}$ & $\mathrm{R}$ & - & $\mathrm{R}$ & $\mathrm{R}$ & $\mathrm{R}$ \\
\hline Compressor Motor & $\mathrm{R}$ & $\mathrm{R}$ & $\mathrm{R}$ & $\mathrm{R}$ & $\mathrm{R}$ & $\mathrm{R}$ & $\mathrm{R}$ & $\mathrm{R}$ & $\mathrm{R}$ & $\mathrm{R}$ & $\mathrm{R}$ \\
\hline Traction Motor & $\mathrm{R}$ & - & $\mathrm{R}$ & - & $\mathrm{R}$ & $\mathrm{R}$ & - & M & $\mathrm{R}$ & $\mathrm{R}$ & $\mathrm{R}$ \\
\hline
\end{tabular}

Table 5. Predictive maintenance scheduling table for case 1 using BPSO (reliability = $52.03 \%$, Cost $=12,579,732.45$ Rands).

\begin{tabular}{|c|c|c|c|c|c|c|c|c|c|c|c|}
\hline $\begin{array}{l}\text { Month No. } \\
\text { Equipment }\end{array}$ & 3 & 6 & 9 & 11 & 14 & 17 & 20 & 23 & 27 & 30 & 33 \\
\hline $\mathrm{MA} / \mathrm{MG}$ & $\mathrm{R}$ & $\mathrm{R}$ & $\mathrm{R}$ & $\mathrm{R}$ & $\mathrm{R}$ & $\mathrm{R}$ & $\mathrm{R}$ & $\mathrm{R}$ & $\mathrm{R}$ & $\mathrm{R}$ & $\mathrm{R}$ \\
\hline Exhauster Motor & $\mathrm{R}$ & $\mathrm{R}$ & $\mathrm{R}$ & $\mathrm{R}$ & $\mathrm{R}$ & $\mathrm{R}$ & $\mathrm{R}$ & $\mathrm{R}$ & $\mathrm{R}$ & $\mathrm{R}$ & $\mathrm{R}$ \\
\hline Compressor Motor & $\mathrm{R}$ & $\mathrm{R}$ & $\mathrm{R}$ & $\mathrm{R}$ & $\mathrm{R}$ & $\mathrm{R}$ & $\mathrm{R}$ & $\mathrm{R}$ & $\mathrm{R}$ & $\mathrm{R}$ & $\mathrm{R}$ \\
\hline Traction Motor & $\mathrm{R}$ & - & $\mathrm{R}$ & - & - & $\mathrm{R}$ & $\mathrm{M}$ & $\mathrm{R}$ & - & $\mathrm{R}$ & - \\
\hline
\end{tabular}




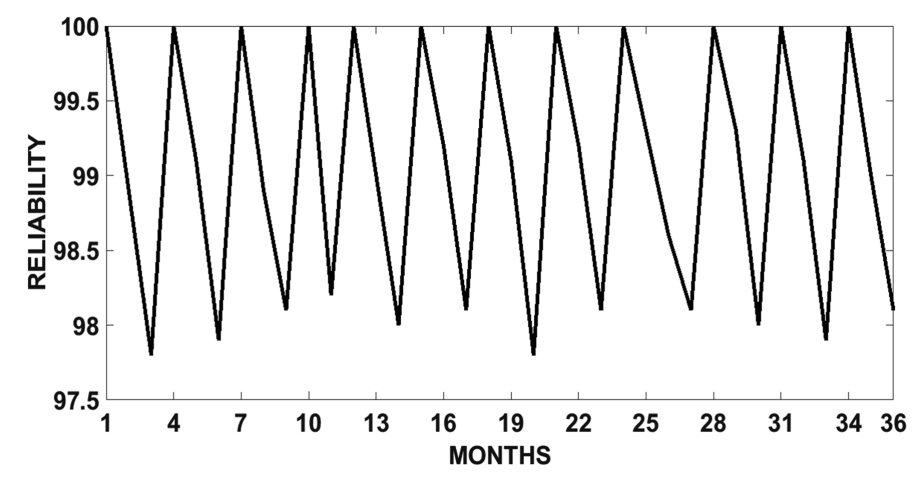

Figure 1. Reliability using PBSO for case 1.

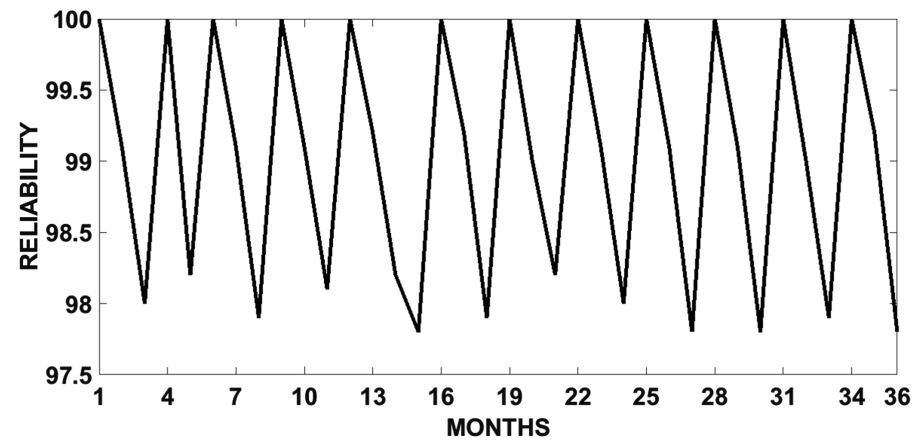

Figure 2. Reliability using PBSO for case 2.

Table 6. Predictive maintenance scheduling table for case 2 using BPSO (reliability = 51.94\%, Cost $=12,510,299.90$ Rands).

\begin{tabular}{|c|c|c|c|c|c|c|c|c|c|c|c|}
\hline $\begin{array}{l}\text { Month No. } \\
\text { equipment }\end{array}$ & 3 & 5 & 8 & 11 & 15 & 18 & 21 & 24 & 27 & 30 & 33 \\
\hline MA/MG & $\mathrm{R}$ & $\mathrm{R}$ & $\mathrm{R}$ & $\mathrm{R}$ & $\mathrm{R}$ & $\mathrm{R}$ & $\mathrm{R}$ & $\mathrm{R}$ & $\mathrm{R}$ & $\mathrm{R}$ & $\mathrm{R}$ \\
\hline Exhauster Motor & $\mathrm{R}$ & $\mathrm{R}$ & $\mathrm{R}$ & $\mathrm{R}$ & $\mathrm{R}$ & $\mathrm{R}$ & $\mathrm{R}$ & $\mathrm{R}$ & $\mathrm{R}$ & $\mathrm{R}$ & $\mathrm{R}$ \\
\hline Compressor Motor & $\mathrm{R}$ & $\mathrm{R}$ & $\mathrm{R}$ & $\mathrm{R}$ & $\mathrm{R}$ & $\mathrm{R}$ & $\mathrm{R}$ & $\mathrm{R}$ & $\mathrm{R}$ & $\mathrm{R}$ & $\mathrm{R}$ \\
\hline Traction Motor & - & - & $\mathrm{R}$ & - & $\mathrm{R}$ & - & $\mathrm{R}$ & - & $\mathrm{R}$ & $\mathrm{R}$ & - \\
\hline
\end{tabular}

For Case 2, Referring to Table 4 and Table 6, there are six months that are commons in activities (months no. 3, 21, 24, 27, 30, 33) among them there are two months that have similar activities (Months no. 27, 30) during the whole interval. However, the preventive maintenance activity is not used at all in BPSO while used twice in GA (Exhauster motor in month no. 7 and traction motor in month no. 24). Thus, unlike Case 1, BPSO makes local search to exploit the existing searched regions in the search space to obtain better solutions than GA.

Thus, the BPSO realizes the adequate balance between the global search (exploration) and the local search (exploitation) leading to the precise alignment of activities to reduce the expected number of failures (ROCOF) and consequently the failure cost leading to increasing the reliability and reducing costs in designing the predictive maintenance scheduling table for railways rolling stocks. 


\section{Conflicts of Interest}

The authors declare no conflicts of interest regarding the publication of this paper.

\section{References}

[1] Dinmohammadi, F., Alkali, B. and Shafiee, M. (2016) A Risk-Based Model for Inspection and Maintenance of Railway Rolling Stock. In: Walls, L., Revie, M. and Bedford, T., Eds., Risk, Reliability and Safety. Innovating Theory and Practice: Proceedings of ESREL 2016, Routledge, London, 1165-1172.

[2] Scarf, P., Alkali, B., Cavalcante, C., Berrade, M.D. and Tait, C. (2012) A Study of the Efficacy of Inspection of Railway Rolling Stock. Annual European Safety and Reliability Conference 2012, Helsinki, 25-29 June 2012, 335-340.

[3] Pedregal, D.J., García, F.P. and Schmid, F. (2004) RCM2 Predictive Maintenance of Railway Systems Based on Unobserved Components Models. Reliability Engineering \& System Safety, 83, 103-110. https://doi.org/10.1016/j.ress.2003.09.020

[4] Podofillini, L., Zio, E. and Vatn, J. (2006) Risk-Informed Optimization of Railway Tracks Inspection and Maintenance Procedures. Reliability Engineering and System Safety, 91, 20-35. https://doi.org/10.1016/j.ress.2004.11.009

[5] Asekun, O.O. and Jacobus Fourie, C. (2015) Selection of a Decision Model for Rolling Stock Maintenance Scheduling. South African Journal of Industrial Engineering, 16, 135-149. https://doi.org/10.7166/26-1-1068

[6] Francois Conradie, P.D., Fourie, C.J., Vlok, P.J. and Treurnicht, N.F. (2015) Quantifying System Reliability in Rail Transportation in an Ageing Fleet Environment. South African Journal of Industrial Engineering, 26, 128-142. https://doi.org/10.7166/26-2-1076

[7] Pievatolo, A., Ruggeri, F. and Argiento, R. (2003) Bayesian Analysis Andprediction of Failures in Underground Trains. Quality and Reliability Engineering International, 19, 327-336. https://doi.org/10.1002/qre.583

[8] Bouillaut, L., Francois, O. and Dubois, S. (2012) Optimal Metro-Rail Maintenance Strategy Using Multi-Nets Modelling. International Journal of Performability Engineering, 8, 77-90.

[9] Panja, S.C. and Ray, P.K. (2007) Reliability Analysis of a 'Point-and-Point Machine' of the Indian Railway Signaling System. Quality and Reliability Engineering International, 23, 833-848. https://doi.org/10.1002/qre.851

[10] Chattopadhyay, G. and Kumar, S. (2009) Parameter Estimation for Rail Degradation Model. International Journal of Performability Engineering, 5, 119-130.

[11] Thaduri, A. (2020) Nowcast Models for Train Delays Based on the Railway Network Status. International Journal of System Assurance Engineering and Management, 11, 184-195. https://doi.org/10.1007/s13198-020-01002-w

[12] Olumuyiwa, A.O. (2014) A Decision Support Model to Improve Rolling Stock Maintenance Scheduling Based on Reliability and Cost. Master's Thesis, Stellenbosch University, Stellenbosch.

[13] Moghaddam, K.S. and Usher, J.S. (2011) A New Multi-Objective Optimization Model for Preventive Maintenance and Replacement Scheduling of Multi-Component Systems. Engineering Optimization, 43, 701-719. https://doi.org/10.1080/0305215X.2010.512084

[14] Murata, T. and Taki, A. (2009) Many-Objective Optimization for Knapsack Prob- 
lems Using Correlation-Based Weighted Sum Approach. International Conference on Evolutionary Multi-Criterion Optimization, Nantes, 7-10 April 2009, 468-480. https://doi.org/10.1007/978-3-642-01020-0 37

[15] Zhang, Y., Wang, S. and Ji, G. (2015) A Comprehensive Survey on Particle Swarm Optimization Algorithm and Its Applications. Mathematical Problems in Engineering, 2015, Article ID: 931256. https://doi.org/10.1155/2015/931256

[16] Wang, H., Wu, Z., Rahnamayan, S., Liu, Y. and Ventresca, M. (2011) Enhancing Particle Swarm Optimization Using Generalized Opposition-Based Learning. Information Sciences, 181, 4699-4714. https://doi.org/10.1016/j.ins.2011.03.016

[17] Kennedy, J. and Eberhart, R.C. (1995) Particle Swarm Optimization. Proceedings of IEEE International Conference on Neural Networks, Perth, 27 November-1 December 1995, 1942-1948. https://doi.org/10.1109/ICNN.1995.488968

[18] Settles, M. and Soule, T. (2005) Breeding Swarms: A GA/PSO Hybrid. Proceedings of the 7 th Annual Conference on Genetic and Evolutionary Computation, Washington DC, 25-29 June 2005, 161-168. https://doi.org/10.1145/1068009.1068035

[19] Katoch, S., Chauhan, S.S. and Kumar, V. (2021) A Review on Genetic Algorithm: Past, Present, and Future. Multimedia Tools and Applications, 80, 8091-8126.

https://doi.org/10.1007/s11042-020-10139-6

[20] Črepinšek, M., Liu, S.-H. and Mernik, M. (2013) Exploration and Exploitation in Evolutionary Algorithms: A Survey. ACM Computing Surveys, 45, Article No. 35. https://doi.org/10.1145/2480741.2480752

[21] Kvaløy, J.T. and Lindqvist, B.H. (1998) TTT-Based Tests for Trend in Repairable Systems Data. Reliability Engineering \& System Safety, 60, 13-28. https://doi.org/10.1016/S0951-8320(97)00099-9

[22] Lindqvist, B.H. (2006) On the Statistical Modeling and Analysis of Repairable Systems. Statistical Science, 21, 532-551. https://doi.org/10.1214/088342306000000448 